\title{
A Validated Chiral LC Method for the Enantiomeric Separation of Repaglinide on Immobilized Amylose Based Stationary Phase
}

\author{
Kiran Patil, ${ }^{a, b}$ Vipul Rane, ${ }^{a, b}$ Ravindra Yeole $e^{b}$ and Devanand Shinde $e^{*, a}$ \\ ${ }^{a}$ Department of Chemical Technology, Dr. Babasaheb Ambedkar Marathwada University, \\ 431004 Aurangabad, MS, India \\ ${ }^{b}$ Wockhardt Research Centre, 431210 Aurangabad, MS, India
}

\begin{abstract}
Um método de HPLC quiral em fase normal, simples, rápido, isocrático, foi desenvolvido e validado para a separação enantiomérica de repaglinida, ácido $(S)$-(+)-2-etóxi-4- $N$ [1-(2-piperidinofenil)-3-metil-1-butil] aminocarbonilmetil] benzóico, uma substância antidiabética. Os enantiômeros de repaglinida foram resolvidos em uma coluna Chiralpak IA (fase estacionária a base de amilose imobilisada) usando uma fase móvel consistindo de $n$-hexano:etanol:ácido trifluoroacético (80:20:20, v/v/v) a uma vazão de 1,0 $\mathrm{mL} \mathrm{min}^{-1}$. A resolução encontrada entre os enantiômeros foi maior do que 2 no método otimizado. O método desenvolvido foi extensivamente validado e mostrou-se robusto, enantiosseletivo, exato, preciso e adequado para determinação quantitativa de $(R)$-enantiômero na substância a granel e no produto formulado.
\end{abstract}

A simple, rapid, isocratic, normal phase chiral HPLC method was developed and validated for the enantiomeric separation of repaglinide, $(S)-(+)$-2-ethoxy-4- $N$ [1-(2-piperidinophenyl)-3-methyl1-butyl] aminocarbonylmethyl] benzoic acid, an antidiabetic drug substance. The enantiomers of repaglinide were resolved on a Chiralpak IA (immobilized amylose based stationary phase) column using a mobile phase consisting of $n$-hexane:ethanol:trifluoroacetic acid (80:20:0.2, v/v/v) at a flow rate of $1.0 \mathrm{~mL} \mathrm{~min}{ }^{-1}$. The resolution between both enantiomers was greater than 2 in the optimized method. The developed method was extensively validated and proved to be robust, enantioselective, accurate, precise, and suitable for quantitative determination of $(R)$-enantiomer in bulk drug substance and product.

Keywords: repaglinide, enantiomeric purity, chiral LC, method validation

\section{Introduction}

Repaglinide (Figure 1) single enantiomer is chemically $(S)$-(+)-2-ethoxy-4-[N[1-(2-piperidinophenyl)-3-methyl1-butyl]aminocarbonylmethyl] benzoic acid. Repaglinide is fast-acting prandial glucose regulator used in the treatment of type II diabetes. ${ }^{1}$ Repaglinide and sulphonyl ureas such as tolbutamide and glibenclamide, share the common property that they are capable of closing ATP sensitive potassium channels. The ATP channel plays a key role in glucose-dependent insulin secretion from pancreatic beta cells. ${ }^{2}$ Repaglidine, a new carbamoylmethyl benzoic acid derivative, is the first of a new class of oral antidiabetic agent designed to normalize postprandial glucose excursions in patients with type 2 diabetes mellitus. ${ }^{3}$ In common with all active oral

*e-mail: proffshinde@yahoo.co.in hypoglycemic agents, it displays a comparable U-shaped configuration. Repaglinide exerts its effects by binding to a site on plasma membrane of beta cells, thereby closing ATP-sensitive potassium channels. ${ }^{4}$<smiles>CCOc1cc(CC(=O)N[C@@H](CC(C)C)c2ccccc2N2CCCCC2)ccc1C(=O)O</smiles>

Figure 1. Chemical structure of (+)-(S)-repaglinide.

Repaglinide, a novel compound with a nonsulphonylurea structure, was clinically tested as a therapeutic agent. The 
hypoglycemic effects of repaglinide were investigated. Whereas the $(R)$-enantiomer of repaglinide shows only weak hypoglycemic activity, the $(S)$-enantiomer has turned out to be a potent hypoglycemic compound. ${ }^{5} \mathrm{~A}$ few HPLC methods have been reported in the literature for the quantitative determination of repaglinide in tablets, human serum and other biological fluids. ${ }^{6-9}$

Repaglinide is produced as a single isomer and $(R)$-enantiomer could be present as a chiral impurity. An HPLC method was reported in the literature for the enantiomeric separation of repaglinide using chiral AGP (protein based chiral stationary phase) column ${ }^{10}$ and Chiralpak AD-H (amylose based stationary phase) column. ${ }^{11}$ In the reported method ${ }^{10}$ enantiomeric separation achieved using gradient elution. If the reported method is applied for the enantiomeric separation of repaglinide saturation of column required about one and half hour and problem of base line drift occurred, the number of theoretical plates about 5000, peak tailing 1.6, broad peak shape and resolution about 1.85 . In the reported method ${ }^{11}$ resolution is more than 3 , but the run time of analysis is more than $25 \mathrm{~min}$ and this article lacks of drug product analysis.

Separation of enantiomers has become very important in analytical chemistry, especially in the pharmaceutical and biological fields, because some stereoisomers of racemic drugs have quite different pharmacokinetics and different pharmacological or toxicological effects. ${ }^{12}$

In recent years, research has been intensified to understand the aspects of the molecular mechanism for stereoselective biological activities of the chiral molecules. The development of analytical methods for the quantitative analysis of chiral materials and for the assessment of enantiomeric purity is extremely challenging due to the fact that enantiomers possess virtually identical properties. ${ }^{13}$ Recently, much work has been reported describing the use of chiral stationary phases, in conjugation with HPLC, as a way to separate and thereby individually quantitative the enantiomers of an enantiomeric pair. ${ }^{14-16}$ The chiral nature of the drug has made the importance to develop the chiral HPLC method for the enantiomeric purity and quantitative determination of undesired isomer.

A simple and rapid isocratic LC method is often more preferred in ordinary lab. Polysaccharide-based (amylose based) stationary phase are quite popular with wide recognition for direct resolution of enantiomers. The present research work deals with rapid, simple, precise and robust enantioselective isocratic chiral LC method for the enantiomeric separation of repaglinide using an immobilized amylose based chiral stationary phase (Chiralpak IA). This paper deals with the validation of determination of the $(R)$ enantiomer in repaglinide drug substance and drug product.

\section{Experimental}

\section{Chemicals}

Samples of $(R)$-enantiomer and repaglinide were obtained from Torrent Research Centre, Ahemadabad, India. The drug product (EUREPA 2) of repaglinide label claims (repaglinide $2 \mathrm{mg}$, Torrent pharmaceutical, Baddi, India) was purchased from the market. HPLC grade $n$-hexane was purchased from Qualigens Fine chemicals, Mumbai, India. The HPLC grade ethanol and trifluoroacetic acid (TFA) were purchased from Merck Ltd, Mumbai, India.

\section{Equipment}

HPLC system used was an Agilent Technologies (1100 series, Germany), system equipped with auto sampler, quaternary pump, degasser and a UV detector. The output signal was monitored and processed using Agilent chemstation software.

\section{Sample preparation}

The stock solution of $(R)$ and $(S)$-enantiomers of repaglinide $\left(5.0 \mathrm{mg} \mathrm{mL}^{-1}\right)$ was prepared by dissolving appropriate amount of substance in methanol. For quantification of $(R)$-enantiomer in repaglinide, a solution of $0.5 \mathrm{mg} \mathrm{mL}^{-1}$ concentration was used.

\section{Chromatographic condition}

The chromatographic column used was $250 \times 4.6 \mathrm{~mm}$ Chiralpak IA (Daicel Chemical Industries, Ltd., Tokyo, Japan) packed with $5 \mu \mathrm{m}$ particles. The mobile phase was $n$-hexane:ethanol:trifluoroacetic acid (80:20:0.2, v/v/v). The flow rate of the mobile phase was $1.0 \mathrm{~mL} \mathrm{~min}{ }^{-1}$. The column temperature was maintained at $30^{\circ} \mathrm{C}$ and the eluent was monitored at a wavelength $254 \mathrm{~nm}$. The injection volume was $10 \mu \mathrm{L}$.

\section{Method development}

The racemic mixture was prepared by physical mixing of equal proportions of $(R)$ and $(S)$-repaglinide $(0.5 \mathrm{mg}$ of each sample). A $0.25 \mathrm{mg} \mathrm{mL}^{-1}$ solution of racemic mixture was prepared in mobile phase and used for the method development. To develop the suitable chiral HPLC method for the separation of the enantiomers of repaglinide, different mobile phases were employed. Various experiments were carried out to select the best mobile phase that would give the optimum resolution and selectivity for the two enantiomers. 
The enantiomeric separation for repaglinide was not achieved by using 2-propanol on Chiralpak IA column. There was an indication of separation on Chiralpak IA column using the mobile phase consisting of $n$-hexane:ethanol (80:20, v/v) but the peak shapes were sligthly broad. For further improvement in resolution, peak shape and column efficiency, the peak modifier trifluoroacetic acid was used. Interesting observations was found when $0.2 \%$ trifluoroacetic acid was used in the mobile phase; both the peak shape and resolution were improved. Very good separation was achieved on Chiralpak IA column (resolution between enantiomers was found to be $>2$ ) using the mobile phase $n$-hexane:ethanol:trifluoroacetic acid (80:20:0.2, v/v/v).

\section{Method validation}

\section{System suitability}

The system suitability was determined by injecting racemic mixture containing equal quantity of $(R)$ and $(S)$-enantiomers. Since the enantiomers form a critical pair of peaks in the chromatogram, the qualification criteria was resolution between two enantiomers, shown to be not less than 2 and tailing factor should not exceed 1.5.

\section{Precision}

Method reproducibility was determined by measuring repeatability and intermediate precision (between-day precision) of retention times and peak areas for each enantiomer.

In order to determine the repeatability of the method, replicate injections $(\mathrm{n}=6)$ of a $0.5 \mathrm{mg} \mathrm{mL}^{-1}$ solution containing $(S)$-repaglinide spiked with $(R)$-enantiomer $(0.5 \%)$ was carried out. The intermediate precision was also evaluated over three days by performing six successive injections each day.

\section{Linearity of $(R)$-enantiomer}

Linearity was assessed by preparing six calibration sample solutions of $(R)$-enantiomer covering from $0.65 \mu \mathrm{g} \mathrm{mL}^{-1}$ (LOQ) to $3.75 \mu \mathrm{g} \mathrm{mL}^{-1}(0.65,1.25,2,2.5$, 3 and $\left.3.75 \mu \mathrm{g} \mathrm{mL}^{-1}\right)$, prepared in mobile phase from $(R)$-enantiomer stock solution.

Regression curve was obtained by plotting peak area versus concentration, using the least squares method. The percentage relative standard deviation of the slope and Y-intercept of the calibration curve was calculated.

\section{Quantification of $(R)$-enantiomer in bulk drug substance and product}

The bulk drug substance and product did not show the presence of $(R)$-enantiomer; therefore standard addition and recovery experiment were conducted to determine the accuracy of the present method for the quantification of $(R)$-enantiomer.

The study was carried out in triplicate at $0.4,0.5$ and $0.6 \%$ of the $(S)$-repaglinide target analyte concentration. The recovery of $(R)$-enantiomer was calculated by determining recovery of the spiked amount of $(R)$-enantiomer in repaglinide.

Limit of detection and limit of quantification of $(R)$-enantiomer

Limit of detection and limit of quantification of $(R)$-enantiomer were achieved by injecting a series of dilute solutions of $(R)$-enantiomer. ${ }^{17}$

The precision of the developed enantioselective method for $(R)$-enantiomer at limit of quantification was checked by analyzing six test solutions prepared at LOQ level and calculating the percentage relative standard deviation of area.

\section{Robustness of the methods}

To determine robustness of the method, experimental conditions were purposely altered, and chromatographic resolution between enantiomers was evaluated.

The flow rate of the mobile phase was $1.0 \mathrm{~mL} \mathrm{~min}^{-1}$. To study the effect of flow rate on resolution of enantiomers, it was changed 0.1 units from 0.9 to $1.1 \mathrm{~mL} \mathrm{~min}^{-1}$. The effect of change in percent of ethanol on resolution was studied by varying from -1 to $+1 \%$ while the other mobile phase components were held constant, as stated in chromatographic condition section. The effect of column temperature on resolution was studied at $28{ }^{\circ} \mathrm{C}$ and $32{ }^{\circ} \mathrm{C}$ instead of $30^{\circ} \mathrm{C}$ while other mobile phase components were held constant, as stated in chromatographic condition section.

\section{Solution stability and mobile phase stability}

Stability of $(S)$-repaglinide in solution at analyte concentration was studied by keeping the solution in tightly capped volumetric flask at room temperature on laboratory bench for 2 days. Content of $(R)$-enantiomer was checked at $6 \mathrm{~h}$ intervals up to the study period.

Mobile phase stability was carried out by evaluating the content of $(R)$-enantiomer in $(S)$-repaglinide. For 2-days same mobile phase was used during the study period.

\section{Results and Discussion}

The mechanism of separation in direct chiral separation methods is the interaction of chiral stationary phase (CSP) with enantiomer that is analyte to form short-lived, transient diastereomeric complexes. The complexes are formed as a result of hydrogen bonding, dipole-dipole interactions, pi bonding, electrostatic interactions, and inclusion complexation. ${ }^{18}$ 
The chiral stationary phase (CSP) that gave the best separation was Chiralpak IA which is 3,5-dimethylphenylcarbamate-amylose derivative immobilized on silica gel. The separation of enantiomers on Chiralpak IA was due to the interaction between the solute and the polar carbamate group on the CSP. The carbamate group on the CSP interacts with the solute through hydrogen bonding using $\mathrm{C}=\mathrm{O}$ and $\mathrm{NH}$ groups present in both the CSP and repaglinide. In addition the dipole-dipole interaction occurs between the $\mathrm{C}=\mathrm{O}$ group on the $\mathrm{CSP}$ and $\mathrm{C}=\mathrm{O}$ group on the repaglinide.

Repaglinide is an acidic compound and to prevent peak tailing from the presence of extra high activity, small amount of trifluoroacetic acid was used in the mobile phase, to help block active sites and improve peak symmetry. Introduction of trifluoroacetic acid in the mobile phase enhanced the chromatographic efficiency, peak symmetry and resolution between the enantiomers. It played an important role for the improvement of resolution, column efficiency and peak shape.

The immobilized amylose-based stationary phase in Chiralpak IA column has higher selectivity than protein based (chiral AGP) and amylose based (Chiralpak AD-H) columns, being suitable for the enantioselective separation and accurate quantification of $(R)$-repaglinide. Another advantage of Chiralpak IA column is their greater stability under normal operation than other Daicel chiral columns. Immobilized column have good stability to strong solvents like THF, ethyl acetate, and chlorinated solvents. Using immobilized stationary phase columns allows a great freedom of solvent choices.

A representative chromatogram of the enantiomeric resolution of repaglinide was shown in Figure 2a. An excellent resolution $(\mathrm{Rs}=2.32)$ between two enantiomers and ideal peak shape with tailing factor 1.19 was obtained. The system suitability test results of the chiral liquid chromatographic method on Chiralpak IA are presented in (Table 1).

Table 1. System suitability results

\begin{tabular}{lcc}
\hline Parameter & $R$ & $S$ \\
\hline Retention time / min & 4.4 & 5.1 \\
Resolution $\left(\mathrm{R}_{\mathrm{s}}\right)$ & & 2.28 \\
USP Tailing & 1.19 & 1.26 \\
Theoretical plates & 5145 & 5292 \\
\% RSD retention time & 0.32 & 0.25 \\
\% RSD peak area & 0.8 & 0.6 \\
\hline
\end{tabular}

Validation results

In the precision study, the percentage relative standard deviation (RSD) was less than $0.5 \%$ for the retention times of the enantiomers, $0.6 \%$ for $(S)$-repaglinide peak area and
$0.8 \%$ for $(R)$-enantiomer peak area. In the intermediate precision study, the results showed that R.S.D. values were in the same order of magnitude than those obtained for repeatability.

The limit of detection (LOD) and limit of quantification (LOQ) concentration were estimated to be 0.2 and $0.65 \mu \mathrm{g} \mathrm{mL}{ }^{-1}$ for $(R)$-enantiomer, when signal-to-noise ratio of 3 and 10 were used as the criteria. The method precision for $(R)$-enantiomer at limit of quantification was less than $1.5 \mathrm{RSD} \%$

The described method was linear in the range of 0.65 to $3.75 \mu \mathrm{g} \mathrm{mL} \mathrm{m}^{-1}$ for $(R)$-enantiomer in repaglinide. The calibration curve was drawn by plotting the peak area of $(R)$-enantimer verses its corresponding concentration with correlation coefficient of 0.999 . The equation of the calibration curve for $(R)$-enantiomer was $\mathrm{Y}=4.7446 \mathrm{x}-1.1502$. The percentage relative standard deviation of the slope and Y-intercept of the calibration curve were 1.2 and 1.5 respectively.

The recovery and standard addition experiments were conducted for $(R)$ enantiomer in bulk samples in triplicate at $0.4,0.5$ and $0.6 \%$ of the analyte concentration. Percentage recovery ranged from 98.5 to $101.5 \%$.

A HPLC chromatogram of $(R)$-enantiomer is shown in Figure 2b, a HPLC chromatogram of spiked $(R)$-enantiomer at $0.5 \%$ level in $(S)$-repaglinide sample is shown in Figure $2 \mathrm{c}$ and a HPLC chromatogram of repaglinide tablet is shown in Figure 2d.

The chromatographic resolution of the $(S)$-repaglinide and $(R)$-enantiomer peaks was used to evaluate the method robustness under modified conditions. The resolution between $(S)$-repaglinide and $(R)$-enantiomer was greater than 2.0 under all separation conditions tested (Table 2), demonstrating sufficient robustness.

Table 2. Robustness of the chiral LC method

\begin{tabular}{cc}
\hline Parameter & $\begin{array}{c}\text { Resolution between } \\
\text { repaglinide and } \\
(R) \text {-enantiomer }\end{array}$ \\
\hline Flow rate / $\left(\mathrm{mL} \mathrm{min}^{-1}\right)$ & \\
0.9 & 2.4 \\
1.0 & 2.3 \\
1.1 & 2.2 \\
Column Temperature / ${ }^{\circ} \mathrm{C}$ & \\
28 & 2.4 \\
30 & 2.3 \\
32 & 2.2 \\
Ethanol percentage in the mobile phase / \% & \\
19 & 2.3 \\
20 & 2.3 \\
21 & 2.2 \\
\hline
\end{tabular}



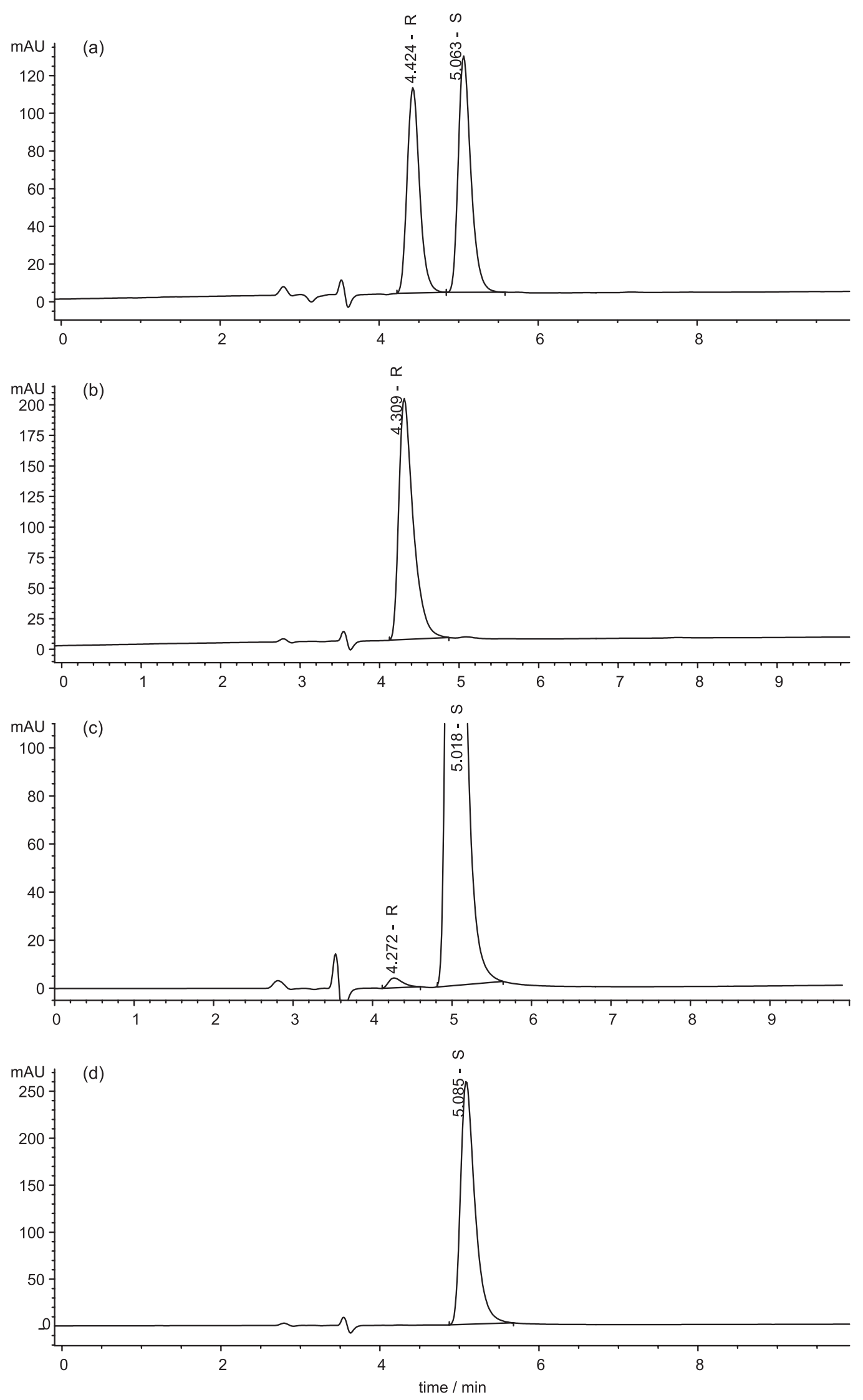

Figure 2. (a) Enantiomeric resolution of repaglinide; (b) HPLC chromatogram of $(R)$-repaglinide; (c) HPLC chromatogram of $(S)$-repaglinide bulk sample $\left(0.5 \mathrm{mg} \mathrm{mL}^{-1}\right)$ spiked with $(R)$-enantiomer $(0.5 \%)$; (d) HPLC chromatogram of $(S)$-repaglinide tablet. 
The RSD\% of ( $R$ )-repaglinide content during solution stability and mobile phase stability experiments was within $1.5 \%$. Hence repaglinide sample solution and mobile phase were stable for at least $48 \mathrm{~h}$.

\section{Conclusions}

A simple, rapid and accurate normal phase chiral HPLC method has been developed and validated for the enantiomeric separation of repaglinide. Chiralpak IA (immobilized amylose-based chiral stationary phase) was found to be selective for the enantiomers of the drug. The method was completely validated showing satisfactory data for all the method validation parameters tested. The developed method can be conveniently used by the quality control department for the quantitative determination of chiral impurity ( $R$-enantiomer) in the bulk material. The developed method is more rapid and enantioselective than reported methods. The developed method shows right order of elution of $(R)$-enantiomer and $(S)$-enantiomer. The developed method is more suitable than the reported methods with respective to resolution $(>2)$, number of theoretical plates $(>5000)$, USP tailing $(<1.3)$, the percentage recovery of the $(R)$-enantiomer between 98.5 to $101.5 \%$.

\section{Acknowledgments}

The authors are thankful to The Head, Department of Chemical Technology, Dr. Babasaheb Ambedkar Marathwada University, Aurangabad, 431004, MS, India, for providing laboratory facility. We are also thankful to Torrent Research Centre (Ahemadabad, India) for providing sample of repaglinide for the research work.

\section{References}

1. Ambavane, V.; Patil, R.; Ainapure, S.; J. Postgrad. Med. 2002, 48, 246.

2. Ashcroft, F. M.; Rorsman, P.; Biochem. Soc. Trans. 1990, 18, 109.

3. Culy, C. R.; Jarvis, B.; Drugs 2001, 61, 1625.

4. Malaisse, W. J.; Eur. J. Clin. Invest. 1999, 2, 21.

5. Mark, M.; Grell, W.; Br. J. Pharmacol. 1997, 121, 1597.

6. Gandhimathi, M.; Ravi, T. K.; Renu, S. K.; Anal. Sci. 2003, 19 , 1675.

7. Berecka, A.; Gumieniczek, A.; Hopakala, H.; J. AOAC Int. 2006, 89, 319.

8. Greischel, A.; Beshke, K.; Rapp, H.; Roth.; J. Chromatogr. 1991, 568, 246.

9. Ruzilawati, A. B.; Wahab, M. S.; Imran, A.; Ismail, Z.; Gan, S. H.; J. Pharm. Biomed. Anal. 2007, 43, 1831.

10. European Pharmacopoeia, $5^{\text {th }}$ ed., Strasbourg, council of Europe, 2007.

11. Rane, V. P.; Shinde, D. B.; Chromatographia 2007, 66, 583.

12. Sahajwalla, C. G.; New Drug Development. Marcel Dekker Inc., New York, 2007, 421.

13. Beesley, T. E.; Scott, R. P. W.; Chiral Chromatography, John Wiley \& Sons Ltd., 1998, 23.

14. Lammerhofer, M.; Gyllenhall, O.; Lindner, W.; J. Pharm. Biomed. Anal. 2004, 35, 259.

15. Bielejewska, A.; Duszezyk, K.; Zukoswski,; J. Acta Chromatogr. $\mathbf{2 0 0 5}, 12,183$.

16. Lu, X.; Liu, P.; Chen, H.; Qin, F.; Li, F.; Biomed. Chromatogr. 2005, 19, 703.

17. International Conference on Harmonisation, Draft Guideline on Validation Procedures, Definitions and Terminology, Federal Register, Fed. 1995, 60, 11260.

18. Kato, M.; Fukushima, T.; Shimaba, N.; Shimada, I.; Kawakami, Y.; Imai, K.; Biomed. Chromatogr. 2001, 15, 227.

Submitted: June 29, 2011

Published online: May 8, 2012 